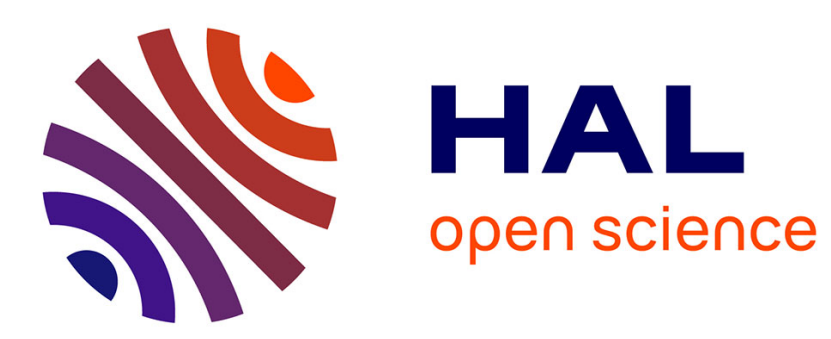

\title{
A method based on C-K Theory for fast STCR development: The case of a drilling robot design
}

Thomas Zedin, Louis Vitalis, Francois Guéna, Olivier Marchand

\section{To cite this version:}

Thomas Zedin, Louis Vitalis, Francois Guéna, Olivier Marchand. A method based on C-K Theory for fast STCR development: The case of a drilling robot design. 34th International Symposium on Automation and Robotics in Construction (ISARC 2017), Jun 2017, Taipei, Taiwan. hal-02868754

\section{HAL Id: hal-02868754 https://hal.science/hal-02868754}

Submitted on 15 Jun 2020

HAL is a multi-disciplinary open access archive for the deposit and dissemination of scientific research documents, whether they are published or not. The documents may come from teaching and research institutions in France or abroad, or from public or private research centers.
L'archive ouverte pluridisciplinaire HAL, est destinée au dépôt et à la diffusion de documents scientifiques de niveau recherche, publiés ou non, émanant des établissements d'enseignement et de recherche français ou étrangers, des laboratoires publics ou privés. 


\title{
A method based on C-K Theory for fast STCR development: The case of a drilling robot design
}

\author{
T. Zedin ${ }^{\text {b }}$, L. Vitalis ${ }^{a}$, F. Guéna ${ }^{a}$ and O. Marchand ${ }^{b}$ \\ ${ }^{a}$ UMR MAP-MAACC, National architecture school of Paris La Villette, France \\ ${ }^{b}$ Research and development, Vinci Construction France, France \\ E-mail: thomas.zedin@ vinci-construction.fr, louis.vitalis@ paris-lavillette.archi.fr, françois.guena@paris- \\ lavillette.archi.fr, olivier.marchand@ vinci-construction.fr
}

\begin{abstract}
-
New products in mechatronics, and especially the spreading of microcontrollers, allow a rise in robotic projects of building construction companies. This new context gives the ability to non mechatronic experts to develop building sites robotics.

In this paper we will describe the design process of a drilling robot prototype made in our Research and Development department. This specific project was constrained by a lack of specifications, and required fast and low cost methods. We had to face the risk of information loss and mistakes in the appreciation of the results. We intend to explain the design methods and knowledge used in the management of this project.

The use of design theories and methods seem to be necessary. Example such as Axiomatic Design or TRIZ can be too strict or too distant from a specific design case. We assume that $\mathrm{C}-\mathrm{K}$ Theory developed by A.Hatchuel and $B$.Weil can be a relevant design tool for the development of robotics projects in construction. Thus we wish to present in this article the way we use the $C$-K Theory to analyze our design process. This design theory is based on two spaces: the knowledge space $K$ and the concept space $C$. It will reveal the concept and knowledge mechanics in our projects and give clues to produce methods for the management of similar projects such as SingleTask Construction Robots.
\end{abstract}

Keywords -

C-K Theory; Construction robotics; Design process modeling; Design methods; Knowledge management; STCR; Drilling robot

\section{Introduction}

The evolutions of the mechatronics have allowed the general contractor Vinci, to realize a drilling robot prototype. The design process was driven by its $R \& D$ department. A particular task in rehabilitation led the specifications: Floors extensions or reinforcements on existing walls. This task use conventional techniques of reinforced concrete industry: Steels implantation and concrete pouring into a formwork. The motivation to create a robot comes from the difficulties generated by multiple drilling prior to the sealing of steels. These drilling are numerous, repetitive and cause ergonomic issues on worksite. These conditions are challenged in the context of labor legislation in France.

We have decided to carry out an analysis of the design process in order to enhance this work, by extending it or making it reproducible. We sought to know what had been contributing to the progress of this project, while maintaining the objectives of reducing the means and time of production. To do this we turn to theories of design.

Various theories of design and innovation emerge in the industrial context. The project we are going to study is similar to Single-Task Construction Robots (STCR). Refer to the book Robot-Oriented Design [1]: it presents ways to manage innovation in the field of building robotics. However, we do not have fundamentally innovative purpose. Moreover this field has already been explored, and we do not intend to question it in this paper. The TRIZ method also provides innovative design solutions often assimilated to artificial creativity [2]. We are not only interested by the emulation of design. We wish to reconstruct our design process, what TRIZ method does not seem to allow. We can also mention Axiomatic design [3], which was implicitly applied throughout the project. In these conditions, retranscribing its principles does not easily allow us to have the necessary perspective on the project. Finally, we can cite Architecturology. It is not actually a method, but a theory of architectural design. We used it in a previous article focusing on the importance of measurement in robotic and architectural design process [4]. This led us to make assumptions about some characteristic in architectural design to initiate construction robotics projects.

$\mathrm{C}-\mathrm{K}$ theory is a design theory that is both a "design 
theory and a theory of the design reasoning" [5]. It presents itself as a tool capable of modeling and analyzing a design process. This element naturally leads us to this theory, since our study occurs at the end of the design process. We will describe our design process then transcribe it with the $\mathrm{C}-\mathrm{K}$ theory. We will focus on the analysis and hypothesis that allow us to produce a fast and low cost method for the management of STCR development.

\section{Method}

We will present various meaningful elements of the design process leading up to the production of the prototype (Figure 1). Its chronology, its key points, means and expertise involved.

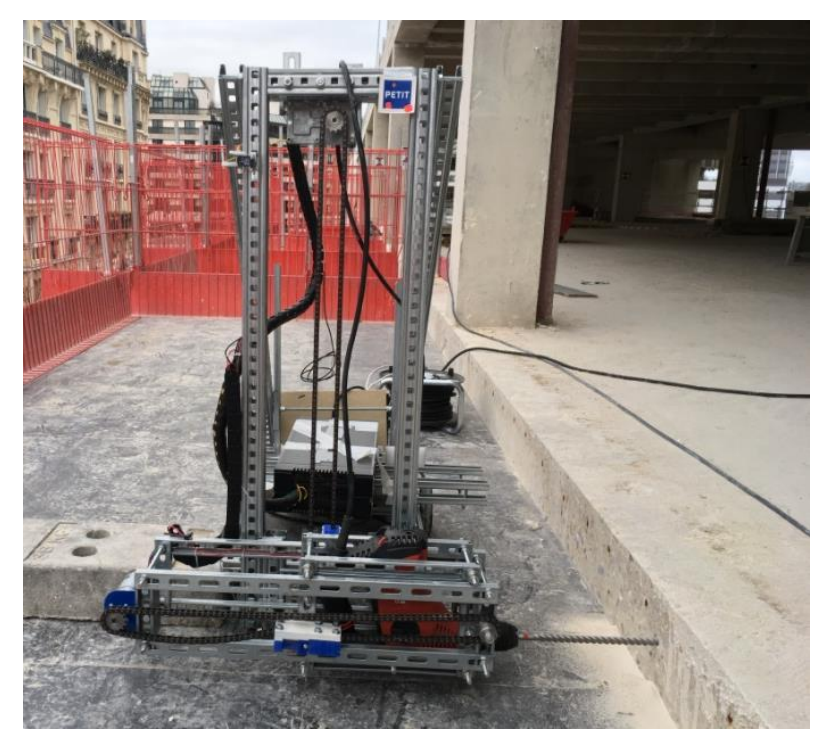

Figure 1. Picture of the drilling robot prototype

This descriptive work will be joined to a modeling of the design process based on the $\mathrm{C}-\mathrm{K}$ theory. We will try to answer several questions: How does the project start? How is the design oriented? What are the means implemented? How to manage them? What is the design mechanics during prototyping?

Modeling of the design process resulted in an analysis of the STCR prototyping project. This will be the basis of proposals for a method adapted to our objectives. We assumed that the management of disruptions, most acquired knowledge, and looking for the most reachable concepts, are compounds of the solution. As mentioned earlier, the fact that the C-K theory presents itself as both a method of analysis and a method of project directs us towards this theory rather than another. To understand it, we will develop its operation in the following sections.

\subsection{C-K Theory Basics}

$\mathrm{C}-\mathrm{K}$ theory is a theory of innovative design. It is used by designers or group of designers in various fields of industry and services. Here is a short list [5] of its applications:

\section{- Management of creativity \\ - Retroconception \\ - Management of an innovation field \\ - Entrepreneurial speech \\ - $\quad$ Project management \\ - Prospection strategy designing \\ - Driving research and knowledge management \\ - Commercial oversight of an innovation line}

The $\mathrm{C}-\mathrm{K}$ theory assumes that the design process is generated by the co-expansion of two spaces. The first one called $\mathrm{C}$ represents the space of concepts while $\mathrm{K}$ represents the space of knowledge [6]. The relationship between these two spaces is defined on the following diagram (Figure 2):

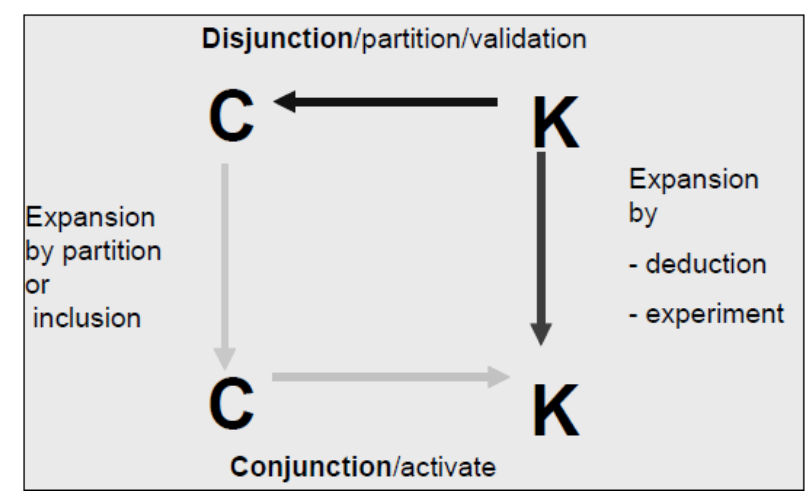

Figure 2. The design square (taken from [6])

We can identify the simplified mechanics of operators between and within the two spaces. This point is important in our study as it allows us to identify the operations sequences of our design process. In addition, the $\mathrm{C}-\mathrm{K}$ theory makes also possible to arrange knowledge and concepts as a diagram, shown in Figure 3.We identify here the expansions in the $\mathrm{K}$ space describing all the propositions that have a logical status (which means the degree of confidence assigned by a designer). And expansions in space $\mathrm{C}$ define as all the propositions that have no logical status described by the designer [5]. We must also notice the concept degrees of expansion (known, reachable, alternative), and the knowledge degrees of robustness (confirmed, in progress, missing). Here we have the basic elements necessary for the construction of our analysis. We will see afterward how we implement them. 


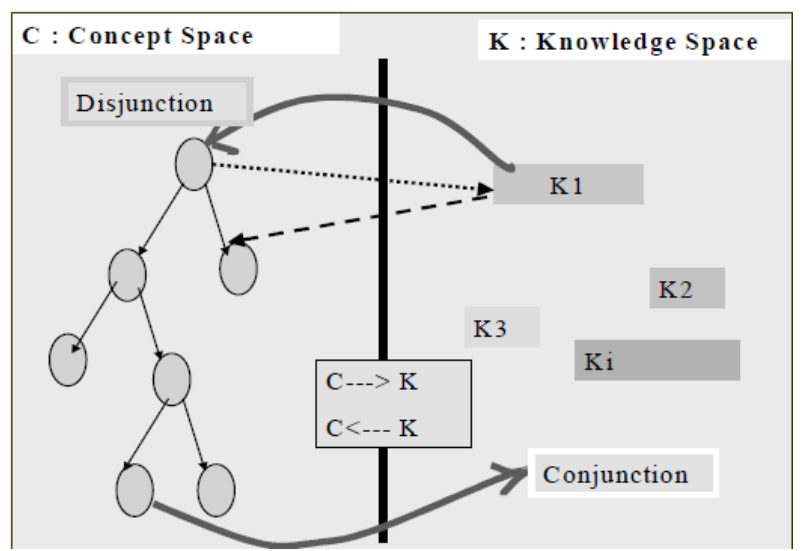

Figure 3. C-K dynamics (taken from [6])

\subsection{The C-K theory as a method of analysis}

As previously announced we have carried out a transcription work of our STCR design case, thanks to the $\mathrm{C}-\mathrm{K}$ theory. This allows us to make variety of diagnosis and to determine relevant management methods for the development of STCR according to our criteria of development. Important point for this research: We intend to produce methods for development management instead of innovation management. C-K theory evokes different forms of design and innovation [7]. For example innovative and rule-based design comparisons, object identity disruptions or dominant design description. Knowing how to specify a design process in relation to these cases gives us clues for the management of a project.C$\mathrm{K}$ theory allows us to understand the design beyond the scope of innovation [8]. We can observe it in the following example (Figure 4).
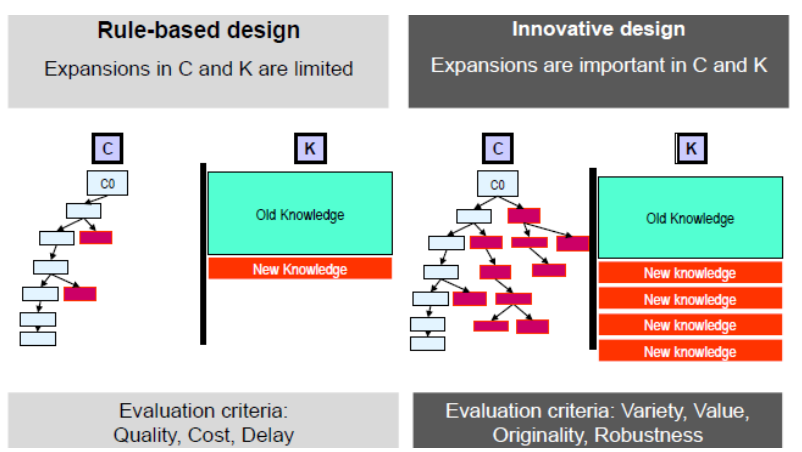

Figure 4. Innovative project evaluation: contrasting product development and innovative design (taken from [8])

This modeling of two design processes synthesizes the fundamental difference between a development project and an innovative project. This difference is identified by the amount of new concepts or knowledge implemented during the design process.

We have no needs to go further in understanding the $\mathrm{C}-\mathrm{K}$ theory for this article, but we suggest you to get a look to the specialized literature on the subject if you wish to do so.

\section{Description of the design process}

The project was carried out in three distinguishable steps involving different expertise. The first step involved only construction site specialists and support. The second step was dedicated to reflections, modeling and proposals in partnership with a robotics company. The last step was the design and production of a prototype inside the construction company. By studying these three steps, we will be able to explore key points of the design process. As we explain, we will focus here on the description of the design process, and put it in line with the $\mathrm{C}-\mathrm{K}$ theory.

\subsection{First step : Specifications drafting}

\subsubsection{Process descriptions}

The project was initiated by the construction site management. A statement related to the difficulties of the drilling tasks in concrete, forced them to find solutions to assist or replace manual labor.

They began the research by collecting knowledge about existing tools close to the problem. The idea of automation was implied in the reflection, but it was arduous to consider by the lack of examples (Figure 5).

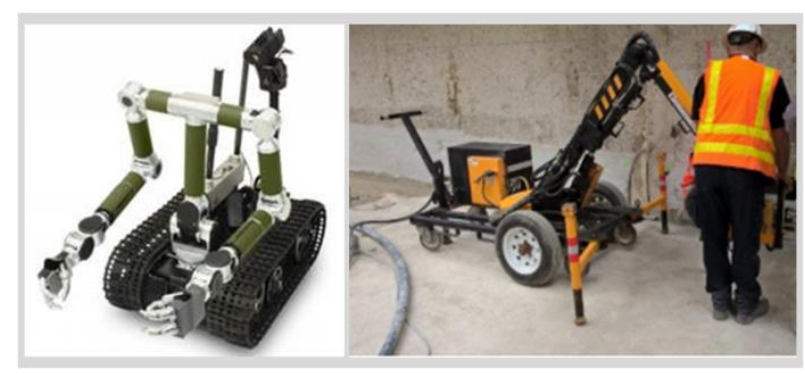

Figure 5. Images used as references by the construction site experts to expose the concept

To assist them in this information-gathering work, they called the company's Materials and R\&D units for help. In the first stage, their support was provided by complementary knowledge on the existing tools to be able to address the problem ([9] and Figure 6).

The absence of solutions coinciding with the problematic provoked the decision to launch a project for the realization of a suitable tool. The exploration did not stop and continued until the end of the process. Nevertheless, the design work proceeded. The 
first characteristics of the tool to be designed were defined as: A robotic system able to assist or automate drilling tasks in concrete.

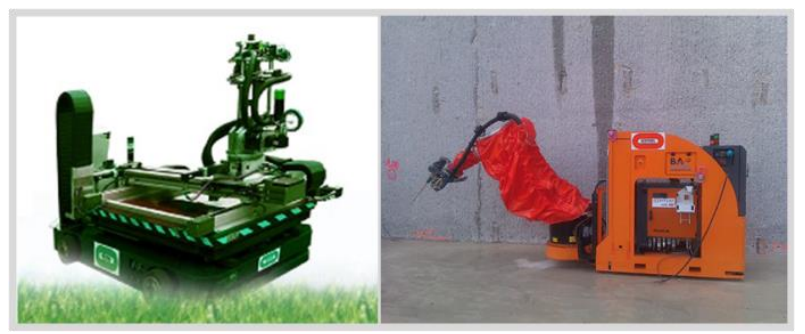

Figure 6. Existing drilling STCR developed in France by general contractor Bouygues Construction.

Yet, the lack of knowledge in robotics within the company could have restrained them to carry out the development of the tool. The rest of the design work had to be assigned to a robotic integrator.

\subsubsection{The design process in a C-K diagram: Step 1}

We deliberately reduce the description of knowledge fields and also the intermediate interactions, to make it easier for the readout. We apply the color code which characterizes the degree of concepts and knowledge appropriation (Figure 7). We represent the starting point of the project, and then the paths from one space to the other and also each state that are induced by these operations.

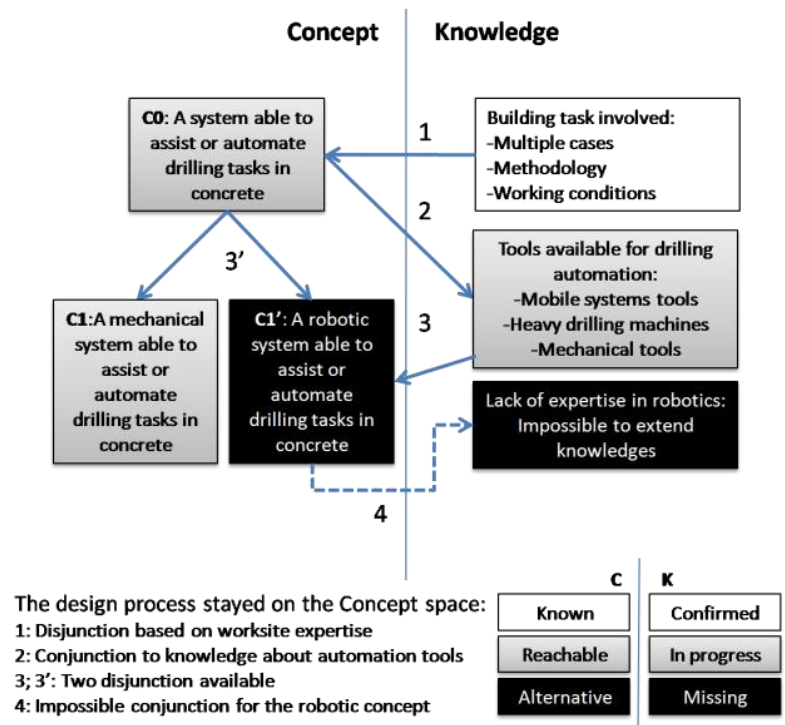

Figure 7. Step 1: Design process modeling with C-K Theory

We notice that the relationship between knowledge and concept is dynamic. There are few expansions taking place within the same space. For example: "building task" expansion going from "working conditions," "multiple cases" then "methodology"; Or even "Tools" expansion going from "mechanical systems" to "automated systems".

We can also analyze the fact that the design process does not start in the space of concepts. The knowledge space induces the different concepts. But the orientation towards a robotic project is a choice towards other concepts. The discarded solutions and the additions to the space of concepts are also identified. This choice is nevertheless constrained and provokes a blocking situation caused by a lack of knowledge in the field of mechatronics. We referred previously in the article. According from the description above, we can see that the $\mathrm{C}-\mathrm{K}$ model helps us to prove the constraint source.

\subsection{Second step : Design mission to a robotics integrator}

\subsubsection{Process descriptions}

The project was assigned to a specialized company in industrial robotics design. The staffs have knowledge within their field, but not in the field of construction. To solve this, we have sent them standard documents (Figure 8) for the management of all construction sites' aspects (methods, safety, planning, etc.).

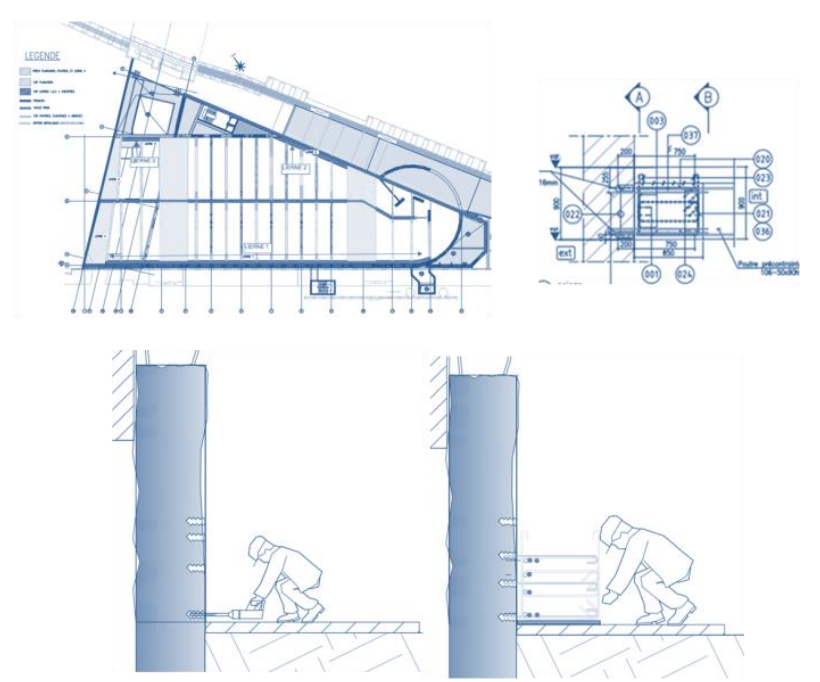

Figure 8. Examples of construction methods documentation

To ensure the spread of the construction site knowledge, we had to complete this approach by visiting the site and observing the task conditions. Despite this, the observation seemed not enough. Industrial robotics integrators are used to work on well-known and modeled environments. We have therefore added digital models presenting some of the 
cases to be treated on our site (Figure 9).

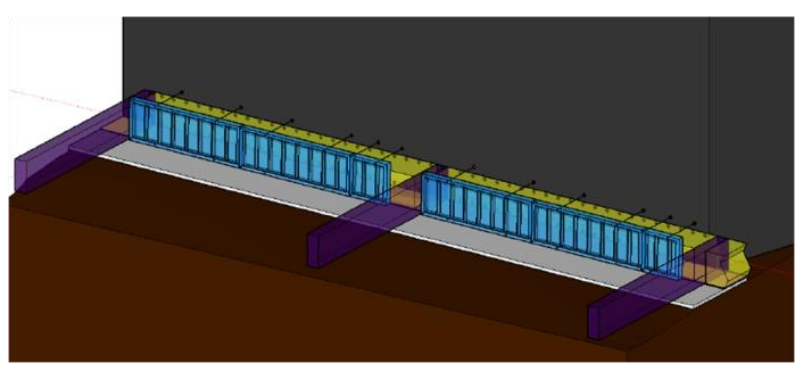

Figure 9. Construction site case digital modeling

The robotic integrators responded through multiple proposals of hybrid systems made of mastered techniques assembly and questioning approach to identify the whole problematic (Figure 10).
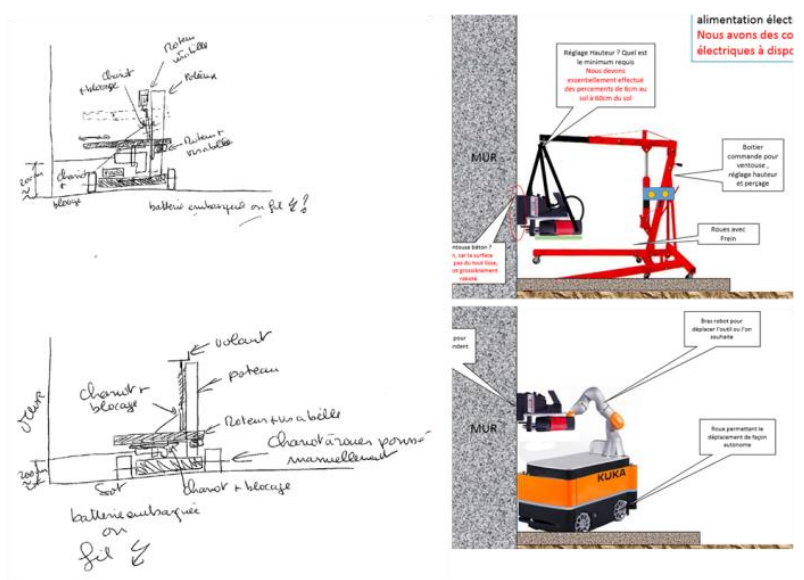

Figure 10. Robotic proposals stage 1

These initial proposals clearly display the design process. But they did not succeed to fix a state of satisfying concepts in regard to the construction company expectations. A second step of the proposals tried to approximate them by increasing the modeling degree of the technical solutions (Figure 11).
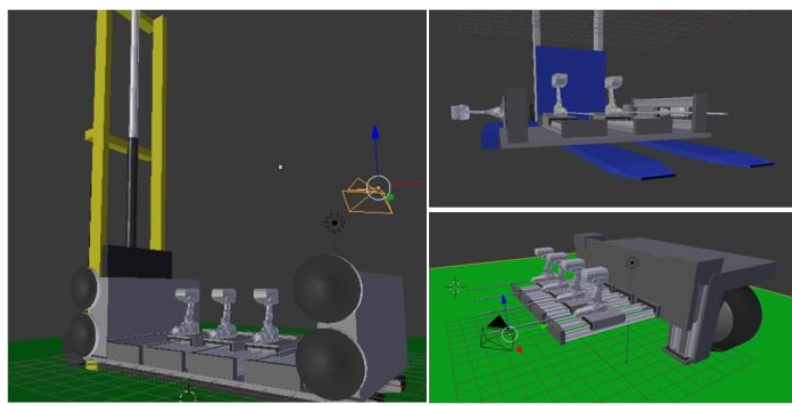

Figure 11. Robotic proposals stage 2

However, there were no viable responses emerging from these proposals. None of the proposals met the specifications. Many aspects seemed to be complicated to manage, such as cost and time of development, but also knowledge related to the general organization of a construction project (traditionally taken into account in other industry sector). The design process was not successful at this stage because none of the proposals seemed to fit.

\subsubsection{The design process in a C-K diagram: Step 2}

Here we can transcribe the process in a $\mathrm{C}-\mathrm{K}$ diagram (Figure 12). The same rules are applied as for the previous diagram. We restart the process from the concept $\mathrm{C} 1$ ' that was fixed in the step 1 , and the expansion in $\mathrm{K}$ that is necessary to the implementation of transmissible specifications to the robotics expert.

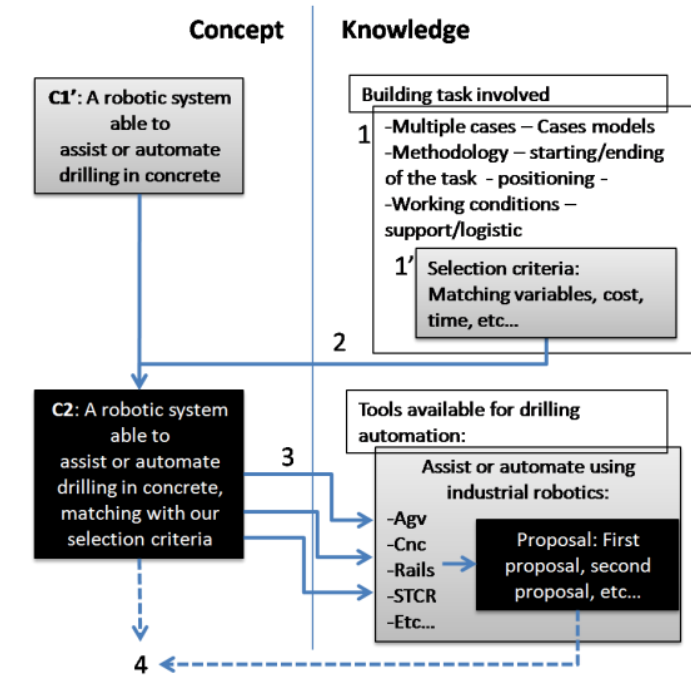

The design process didn't produce new Concept 1: Expansion in $\mathrm{K}$ with working task details $1^{\prime}$ : Expansions in $\mathrm{K}$ with selection criteria 2: Disjunction

3:Conjunction to robotics for proposals 4: Impossible Disjunction

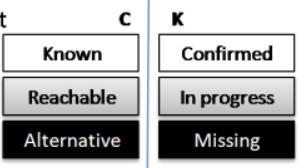

Figure 12. Step 2: Design process modeling with C-K Theory

We observe the interaction inside the knowledge spaces referring to the tools and the construction task concerned. It produces a C2 expansion of concept bounded to the selection criteria drawn from the specifications. We can observe in $\mathrm{C}-\mathrm{K}$ that none of the proposal appears to be a solution as no concept is created at the end of the design process. Proposals are only knowledge exploration and not new concepts expansions.

We have seen in step 1 that an obstruction in the knowledge space has interrupted the design process. We can see here that the concept space is equally important for the advancement of the design process. Identifying 
the origin of the interruption could be one way to ensure the continuity of the project. Nonetheless, we find that the design process does not really pick up where it stops. Expansion of knowledge about the site is required. This result brings us not to confuse the state of common knowledge enlisted during the project and those of each participant.

\subsection{Third step: Prototyping}

The last step is about the production of a prototype. This step took place within the construction company, aware of mastering its needs to the best of its ability. To avoid the problem of lack in mechatronics design knowledge, it relied on specialized human resources for this kind of project. We cannot describe here all the design details, so we will focus on the design choices and the validation methods used.

\subsubsection{Design choices}

Prior to the production of the prototype, we proceeded to a sequence of choices throughout the designs. These were of course directed by the specifications, but also by the exploration of accessible knowledge in mechatronic design. We can list them as:

- Mechanical choices by various assembly solutions.

- Actuator system choices. Combinations of axes such as Cartesian reference.

- Mobility system choices.

- Choice of control, interface, operations implementation of communication systems.

- Choice of the end effectors - (we stated on a commercial drill in order to avoid the design of this part.)

- Choice of automation guidance (not realized). Uses of distance sensors - direct control of the drill.

The quotation order does not indicate the going back and forth in the design. Moreover, most of these choices were based on validation methods which we present in the remainder of this article.

\subsubsection{Design hypothesis validation methods}

Numerous validation methods have been deployed during design and during the production.

- $\quad$ Simulation and Modeling

- Real Movement Tests

- Tests for handling and operation on site

The same assembly can lead us to various means of validations. We had to request for simulations and modeling. In the following case, we have a representation of a simulation process for the mechanical forces calculations and a kinematic modeling for the whole system (Figure 13).

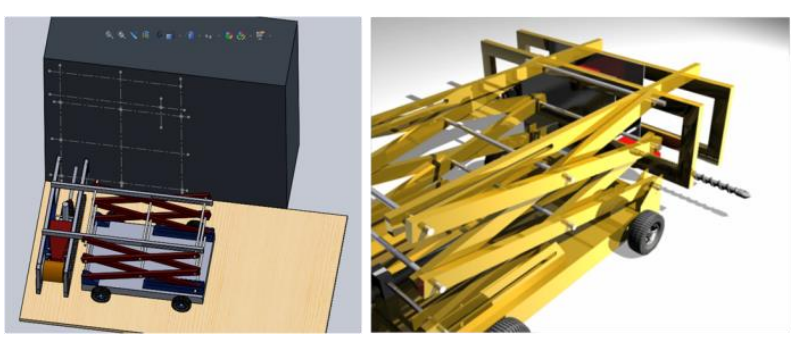

Figure 13. Simulation (left) and Kinematic model (right) of a single state of assembly

Assemblies can also give endless combinations. Some are not mechanically viable while others are too expensive or not optimized. It was necessary to carry out various simulations of complete or partial assemblies (Figure 14).

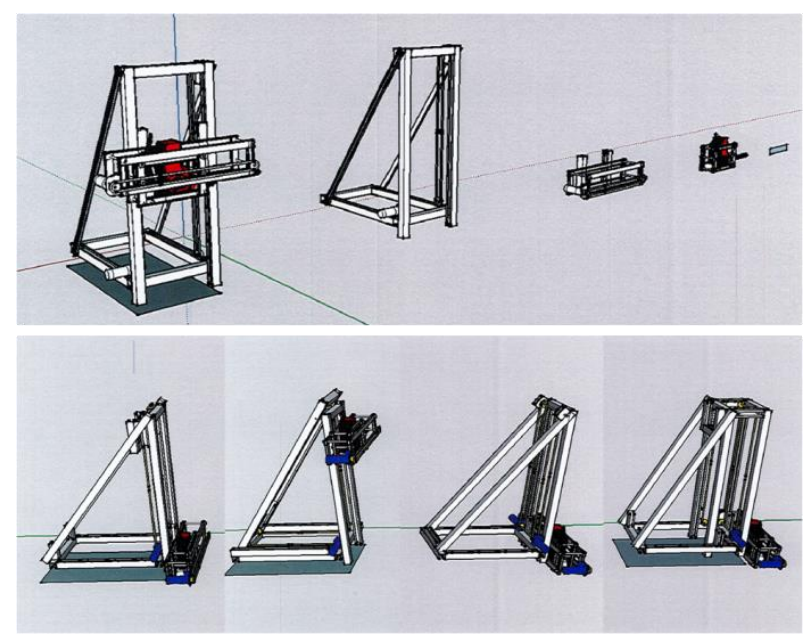

Figure 14. Assembly variation and test

Finally, we carried out relevant or operational environment tests. Designing combined axes and interfaces allowed us to test their proper functioning independently (Figure 15).

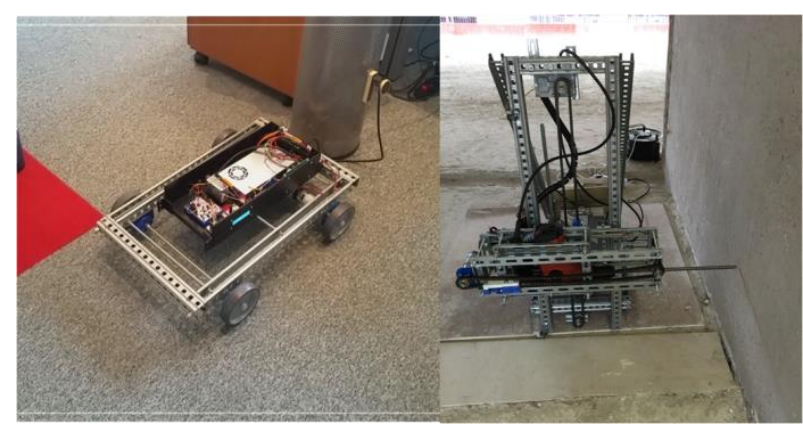

Figure 15. On-site and Off-site prototyping tests 
Beyond the results of the project readiness level given by this kind of tests, we can ask ourselves the question of their relationship within the design process. We will figure out with the $\mathrm{C}-\mathrm{K}$ transcription.

\subsubsection{The design process in a $\mathrm{C}$-K diagram: Step 3}

As the previous steps, we can represent the design process in $\mathrm{C}$ and $\mathrm{K}$ (Figure 16). We resume the design process from the concept $\mathrm{C} 2$, as the previous concepts have been fixed.

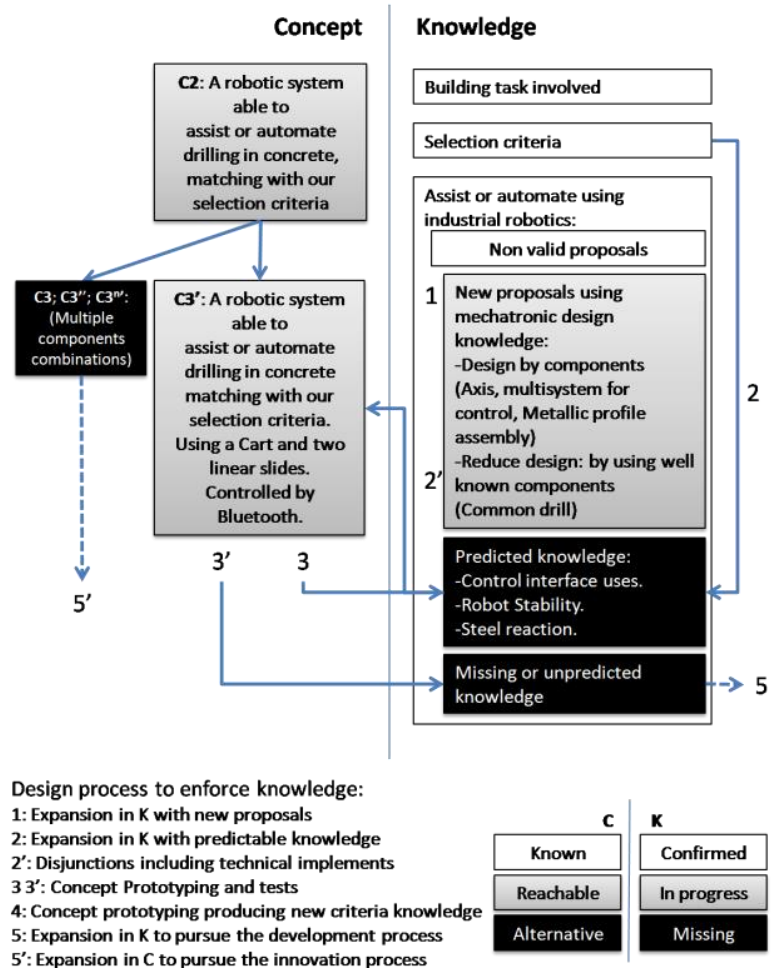

Figure 16. Step 2: Design process modeling with C-K Theory

Including all tests, modeling and simulations on the same diagram can be complicated. However, we can focus on the relationship between knowledge and the multiple concepts created. We observe that the design process takes place in continuity of the previous step. C$\mathrm{K}$ theory can explain this fact by the prototyping dynamic [7]. This dynamic is complex and involves equally the $\mathrm{C}$ and the $\mathrm{K}$ spaces. Each choice of development initiated in $\mathrm{K}$ causes an expansion in $\mathrm{C}$. The prototyping of a solution does not erase the concepts allowed by other assembly choices. On the other hand, prototyping makes it possible to act significantly on the expansion of knowledge. To go further in the analysis we could identify the restrictive characteristics of a STCR project to avoid getting out of this line of concepts. This could be done through diagrams focused on the knowledge space. This work has not yet been carried out, but we plan to do so in the continuity of this research.

We will not specify the choices management in detail, but we can say that the project is driven towards the best mastered knowledge, and the most attainable concepts. We can conclude here with the elements that would allow us to extend the project. We can orient ourselves on expansions derived from not yet prototyped concepts. This can be done by integrating knowledge produced during the first prototype validation process. We can also produce knowledge expansions, in order to extend the first prototypical concept line.

\section{Conclusion : Towards a generic design method for the fast development of STCRs}

Thus, we have been able to transcribe the design process of a STCR project in a descriptive way, and to analyze it from a transcription of the $\mathrm{C}-\mathrm{K}$ model. We have discussed the conclusions we can make for each of the steps, and we will summarize them.

We wished to know what allowed us to maintain the continuity of the design process. Ours conclusion are that we succeeded by involving expertise on the project objectives for the management of knowledge expansions. The objectives are conducted by selection criteria described in the knowledge space, but the continuity vector can be observed in the management of the concepts directed to produce prototypes. The expansions of knowledge within $\mathrm{K}$ spaces are conceivable, but they do not allow us to reach the prototyping step.

Then we posed the question of what allowed us to complete our objectives related to the reduction of means and time needed for the development. The analysis of the step 3 allowed us to answer this question by observing that the design choices were made according to the expansions confidence degree. We conclude that we could aim at the most reachable concepts, and the best mastered knowledge. This could form a guideline for further design process in a similar context.

These findings may concern other development projects than those of the STCR. But we can make assumptions about what determines this particular kind of project. It seems clear that in this case the knowledge structure around the fields of mechatronic technologies and production methods on construction site is specific of STCR development. In addition, what emerges from our analysis is that we can also specify it by the mastery of the concept expansions, restricting them to the STCR field. It answers to another question we introduced 
about what initiated the project. It resulted from a choice to explore this field according to the concepts expansions.

Finally, we observed that the CK theory could help us in analysis, as well as the management with $\mathrm{C}$ and $\mathrm{K}$ expansions. This allows us to reveal the knowledge produced during prototyping and to consider relevant paths toward other prototypes or even the completion of the project.

We pose the question of ways yet to be explored on this subject. We plan to produce more detailed modeling of the relationships between knowledge in the process. We also look at other STCR development projects to verify our assumptions. Other kind of analysis can be made from the $\mathrm{C}$-K modeling that we produced. We do not treat them here because they do not fit with the problematic of this article. Nevertheless we can evoke them: the Risk management during the development or even collaboration management of various expertises during the design process. This research progress still need to be discussed and will be subject of numerous works.

\section{References}

[1] Bock T. and Linner T. Robot-Oriented Design Design and Management Tools for the Deployment of Automation and Robotics in Construction, Cambridge university press, 2015.

[2] Mercier-Laurent E. Intelligence artificielle : peutelle rebooster la créativité humaine ?.In Bulletin de l'AFIA $n^{\circ}$ 78, p 5-8, 2012.

[3] Suh, Nam P. The principles of design. Oxford University Press, 1990.

[4] Zedin T., Guéna F. and Marchand O. La mécatronique dans le processus de conception des outils de construction: La mesure au sein d'un continuum numérique. In Séminaire de conception architecturale numérique: Mètre et paramètre, mesure et démesure du projet,pages 265-274, Toulouse, France, 2016.

[5] Agogué M., Arnoux F., Brown I. and Hooge S. Introduction à la conception innovante. Presses des Mines, 2013.

[6] Hatchuel A. and Weil B. A new approach of innovative design: an introduction to $\mathrm{C}-\mathrm{K}$ Theory. In ICED'03, page 14, Stockholm, Sweden, 2003.

[7] Le Masson P., Weil B. and Hatchuel A. Théorie, methodes et organisations de la conception. Presses des Mines, 2014.

[8] Hatchuel A., Le Masson P., Weil B., Agogué M., Kazakçi A. and Hooge S. Multiple forms of applications and impacts of design theory -ten years of industrial applications of C-K Theory. In Impact of Design Research on Industrial Practices
- Tolls, Technology and Training, 2015.

[9] Publication committee International association for automation and robotics in construction. Robots and Automated Machines in Construction, 1998 